\title{
Pott's disease with extensive bilateral psoas abscesses in a Nigerian woman: an unusual case
}

\author{
Nneka I. Iloanusi ${ }^{1}$, Uche S. Unigwe ${ }^{2}$, Enoch O. Uche ${ }^{3}$, Michael O. Iroezindu²*, Okechukwu C. \\ Okafor $^{4}$
}

\author{
1. Department of Radiation Medicine, Faculty of Medical Sciences, University of Nigeria, Ituku/Ozalla Campus, Enugu, Nigeria \\ 2. Department of Medicine, University of Nigeria Teaching Hospital, Ituku-Ozalla, Enugu, Nigeria \\ 3. Department of Surgery, University of Nigeria Teaching Hospital, Ituku-Ozalla, Enugu, Nigeria \\ 4. Department of Morbid Anatomy, University of Nigeria Teaching Hospital, Ituku-Ozalla, Enugu, Nigeria
}

*Correspondence: Dr Michael O. Iroezindu (mikezindu@yahoo.com)

\begin{abstract}
Bilateral psoas abscesses are uncommon in Pott's disease. We describe a 28-year-old Nigerian woman with a 2-year history of constitutional symptoms and a 1-year history of bilateral paravertebral masses. She had received anti-tuberculosis (TB) treatment in an interrupted manner. A computed tomography (CT) scan revealed T10-T12 spondylitis, wedge collapse and extensive bilateral psoas abscesses. Histology of the abscess wall was definitively diagnosed as soft tissue TB, and special staining for acid-fast bacilli was positive. She was successfully treated with anti-TB therapy and ultrasound-guided surgical drainage of $6 \mathrm{~L}$ of abscess fluid. Complicated cases of Pott's disease may require multi-disciplinary interventions for optimal outcome.

Key Words

Pott's disease, psoas abscess, tuberculosis, ultrasound-guided surgery
\end{abstract}

\section{Case presentation}

A 28-year-old woman presented to the University of Nigeria Teaching Hospital (UNTH) Enugu on February 24, 2015 with a 2-year history of low-grade fever, weight loss, drenching night sweats and a 1-year history of painless bilateral paravertebral swellings. Before this, she had experienced low back/flank pains, difficulty in walking and lower limb paraesthesia, which subsided following 3 months of anti-tuberculosis (TB) therapy in a rural hospital. The treatment was discontinued when she became unable to pay for the drugs. Further review of systems was unremarkable. She had nursed a family member who suffered from TB.

Physical examination revealed a chronically ill-looking young woman who was afebrile and had no signs of neurological dysfunction. Her weight was $49 \mathrm{~kg}$. There were two large paravertebral masses around T10-L4 vertebrae (Figure 1): the right mass measured $16 \times 14 \mathrm{~cm}$; the left mass measured $18 \times 16 \mathrm{~cm}$. The lesions were fluctuant, smooth, without features of acute inflammation. There was a gibbus around T11/T12. The groin had similar masses measuring $10 \times 6 \mathrm{~cm}$ (right) and $10 \times 4 \mathrm{~cm}$ (left). Neurological/other examination findings were normal. The differential diagnoses included Pott's disease with paravertebral abscesses, fungal spondylitis, pyogenic spondylitis and metastatic spinal disease.

Investigation results are summarised in Table 1. Computed tomography (CT) scan findings (spine, abdomen/pelvis) were suggestive of TB spondylitis with bilateral paraspinal hypodense collections extending into the psoas muscle and pelvis (Figure 2A and B). She was commenced on daily antiTB therapy (rifampicin, isoniazid, pyrazinamide, ethambutol plus pyridoxine) under the directly observed therapy shortcourse (DOTS) programme.

On March 23, 2015, ultrasound-guided surgery was performed by the neurosurgical and radiology teams under general anaesthesia leading to complete drainage of yellowish, free-flowing fluids $-3.2 \mathrm{~L}$ and $2.8 \mathrm{~L}$ from the left and right masses, respectively (Figure 3). A wedge biopsy of the abscess wall soft tissue showed dense chronic inflammation with haemorrhage, fibrosis and numerous well-formed granulomas (Figure 4A). Ziehl-Neelsen staining showed occasional acid-fast bacilli within the histiocytes (Figure 4B). Histological diagnosis of paravertebral soft tissue TB was made. Cytology and cultures were negative. The patient's post-operative condition was stable, and she was maintained on the continuation phase of anti-TB treatment. The wound drains were removed following sonographic evidence of complete resolution. The patient was discharged home on May 5, 2015. She completed 12 months of anti-TB treatment and has remained stable (Figure 5).

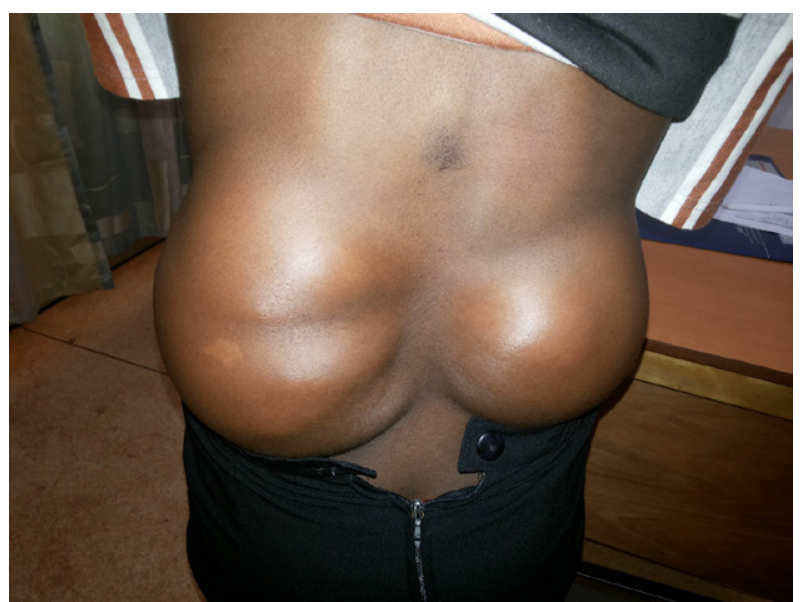

Figure 1. A 28-year old Nigerian woman with bilateral paravertebral masses around $\mathrm{T} 10-\mathrm{L} 4$ vertebrae 
Table 1. Investigation results of a 28-year-old Nigerian woman with Pott's disease complicated by extensive bilateral psoas abscesses

\begin{tabular}{|c|c|}
\hline Parameters & Findings \\
\hline \multicolumn{2}{|l|}{ Haemoglobin (g/dl) } \\
\hline $24 / 02 / 15$ & 12.6 \\
\hline $20 / 03 / 15$ & 11.0 \\
\hline \multicolumn{2}{|l|}{ WBC (total, $\left.\times 10^{3} / \mu l\right)$} \\
\hline $24 / 02 / 15$ & 4.0 \\
\hline $20 / 03 / 15$ & 6.5 \\
\hline \multicolumn{2}{|l|}{ Neutrophils (\%) } \\
\hline $24 / 02 / 15$ & 34.0 \\
\hline 20/03/15 & 58.0 \\
\hline \multicolumn{2}{|l|}{ Lymphocytes (\%) } \\
\hline $24 / 02 / 15$ & 66.0 \\
\hline 20/03/15 & 37.0 \\
\hline Platelets $\left(\times 10^{3} / \mu \mathrm{l}\right)$ & 180 \\
\hline \multicolumn{2}{|l|}{ ESR } \\
\hline $24 / 02 / 15$ & 7 \\
\hline 19/03/15 & 11 \\
\hline $\mathrm{CRP}(\mathrm{mg} / \mathrm{dl})$ & 1.8 \\
\hline HIV I and II antibodies & Negative \\
\hline $\mathrm{HB}_{\mathrm{S}} \mathrm{Ag}$ & Negative \\
\hline Anti-HCV & Negative \\
\hline Serum electrolytes (mmol/L) & $\begin{array}{l}\mathrm{Na}^{+}=138, \mathrm{~K}^{+}=3.9, \mathrm{Cl}^{-}=116 \\
\mathrm{HCO}_{3}=24\end{array}$ \\
\hline Urea (mmol/L) & 4.2 \\
\hline Creatinine $(\mu \mathrm{mol} / \mathrm{L})$ & 88.5 \\
\hline Liver enzymes (IU/L) & $\begin{array}{l}\text { ALP: 88, AST: } 16 \text { IU/L, ALT: } 12 \\
\text { IU/L }\end{array}$ \\
\hline Fasting blood glucose (mmol/L) & 4.4 \\
\hline Urinalysis & Normal \\
\hline Urine MCS & No bacterial growth \\
\hline Sputum MCS & No bacterial growth \\
\hline Sputum AFB & Negative \\
\hline Mantoux test (mm) & 3 \\
\hline INR & 0.89 \\
\hline Psoas abscess MCS & No bacterial growth \\
\hline Psoas abscess fungal studies & No fungal elements or growth \\
\hline Aspirate cytology & $\begin{array}{l}\text { Smear was polymorphous and } \\
\text { showed only histiocytes, plasma } \\
\text { cells, lymphocytes and a few } \\
\text { multinucleated cells. No atypical } \\
\text { cells were present }\end{array}$ \\
\hline
\end{tabular}

table 1 cont....

\begin{tabular}{|c|c|}
\hline Histology of abscess wall soft tissue & $\begin{array}{l}\text { Chronically inflamed soft tissue } \\
\text { with numerous granulomas } \\
\text { consisting of epithelioid } \\
\text { histiocytes, lymphocytes and } \\
\text { Langhans type multinucleated } \\
\text { giant cells. There were no atypical } \\
\text { cells } \\
\text { Conclusion: TB involving } \\
\text { paravertebral soft tissue }\end{array}$ \\
\hline Abscess wall staining for AFB & Positive \\
\hline $\begin{array}{l}\text { X-ray thoraco-lumbar spine } \\
\text { (anteroposterior view) }\end{array}$ & $\begin{array}{l}\text { Anterior wedge collapse of } \\
\text { vertebral bodies; two ribs project } \\
\text { out from the area of collapse } \\
\text { indicating the involvement } \\
\text { of adjacent vertebra and the } \\
\text { intervertebral disc } \\
\text { Conclusion: TB of the spine }\end{array}$ \\
\hline Chest X-ray & Normal findings \\
\hline CT-scan (spine, abdomen/pelvis) & $\begin{array}{l}\text { Bilateral para-spinal elongated } \\
\text { hypodense masses with a } \\
\text { Hounsfield unit of } 19 \text { originating } \\
\text { at the level of T10 vertebral body. } \\
\text { There was associated multifocal } \\
\text { lytic destruction in the spongiosa } \\
\text { and cortex of T10-T12 vertebral } \\
\text { bodies. The masses extended } \\
\text { inferiorly into the belly of the } \\
\text { psoas muscles. At the level of } \\
\text { L3/L4 disc space, the posterior } \\
\text { aspect of the masses herniated } \\
\text { exteriorly into the subcutaneous } \\
\text { tissues of the back. The anterior } \\
\text { aspect of the masses continued } \\
\text { inferiorly into the pelvis and exited } \\
\text { into the thigh through the femoral } \\
\text { canal to terminate at the lesser } \\
\text { femoral trochanter. Volumetric } \\
\text { analysis of the masses revealed } \\
\text { about } 3.2 \text { Lof fluid per side. The } \\
\text { kidneys, aorta, and inferior vena } \\
\text { cava were displaced anteriorly }\end{array}$ \\
\hline
\end{tabular}

AFB: acid-fast bacilli, ESR: erythrocyte sedimentation rate, CRP: C-reactive protein, HBsAg: hepatitis B surface antigen, HCV: hepatitis C virus, HIV: human immunodeficiency, INR: international normalized ratio, MCS: microscopy, culture, and sensitivity,TB: tuberculosis, WBC: white bold cell.

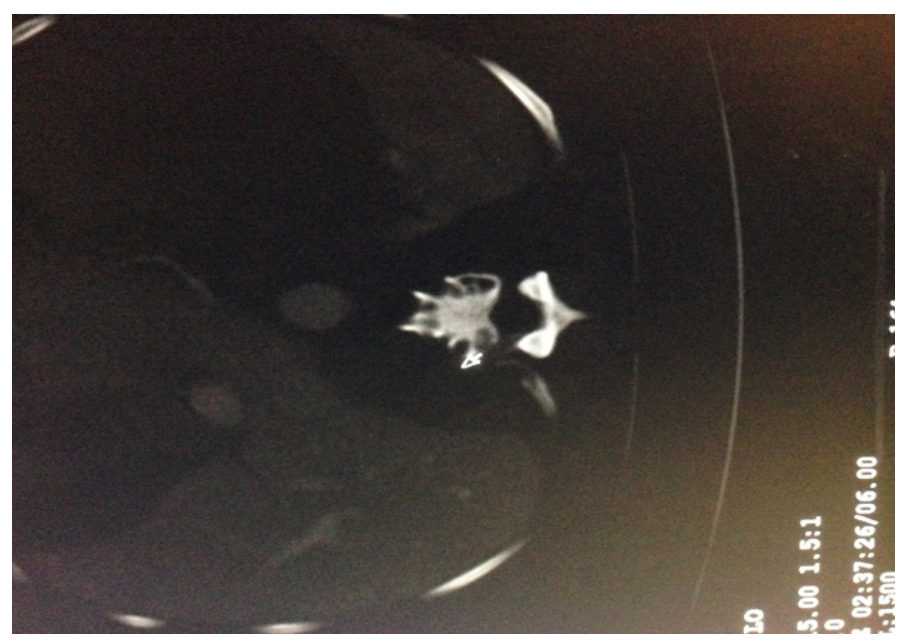

Figure 2. A: CT of the spine (bone window) showing lytic destruction of the spongiosa of the T12 vertebral body. 


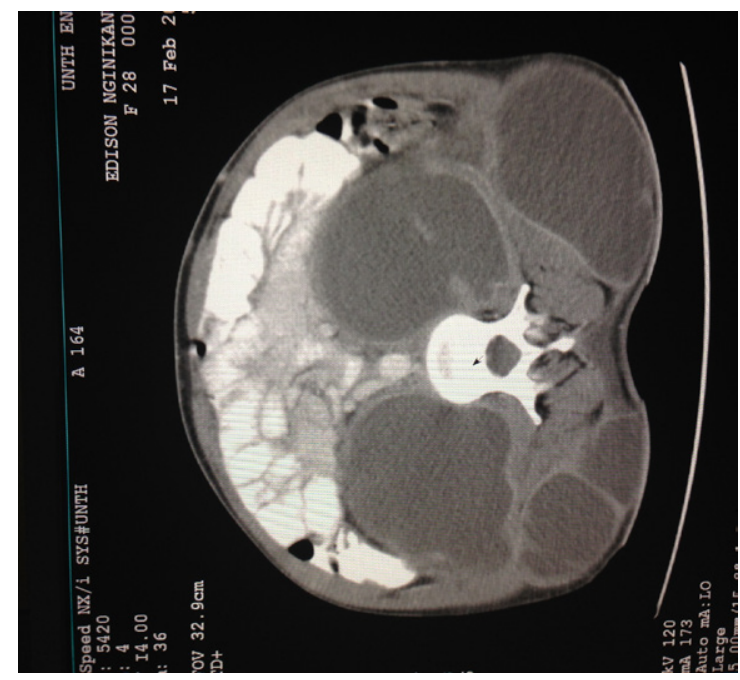

Figure 2. A: CT of the spine (bone window) showing lytic destruction of the spongiosa of the T12 vertebral body.

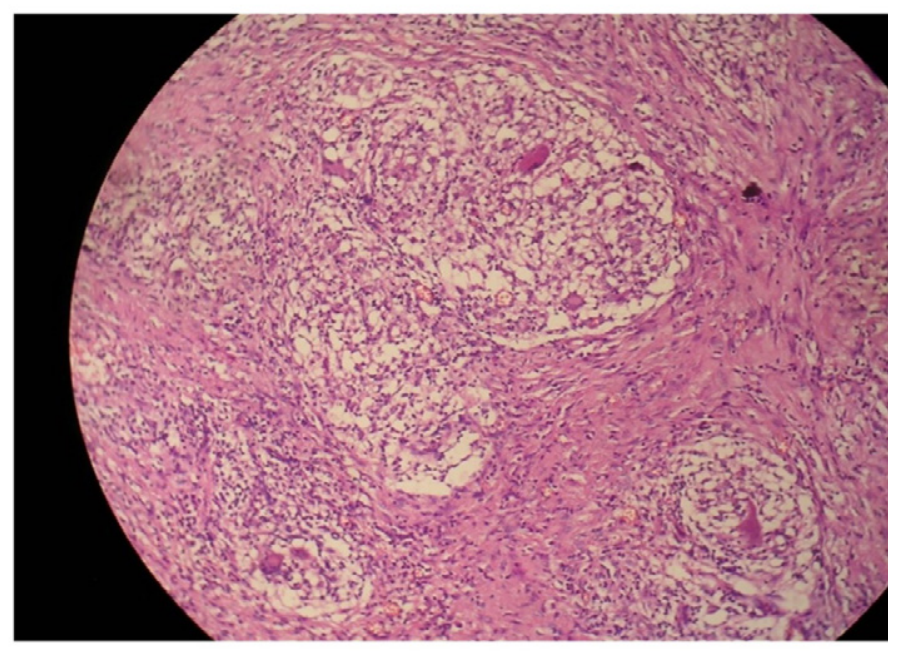

Figure 4. (A) Midline L1-L4 surgical access to large bilateral paravertebral abscesses. (B) Ziehl-Neelsen staining $\times 100$ showing occasional acid-alcohol fast bacilli (circled).

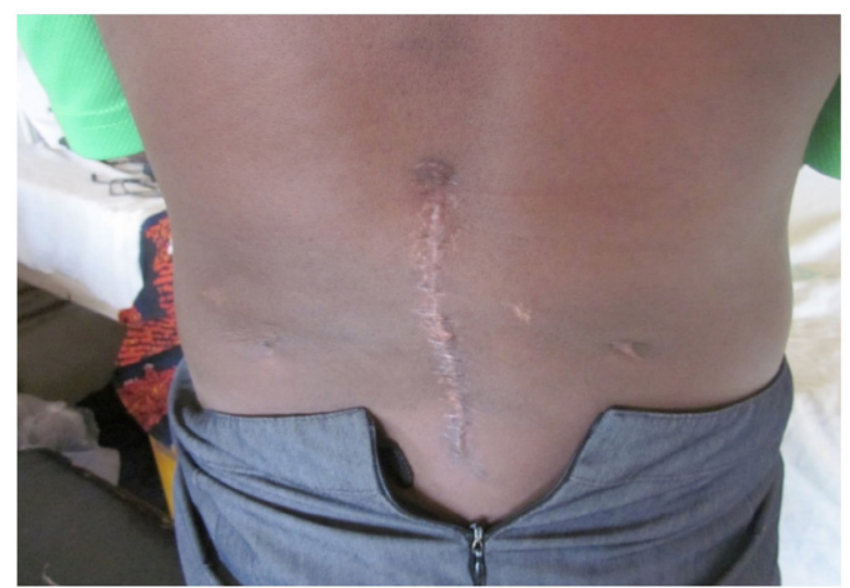

Figure 5. The patient 2 months' post-surgery and after 3 months of anti-TB therapy.

\section{Discussion}

Spinal TB is usually secondary to an extraspinal source of Mycobacterium tuberculosis. It typically affects multiple vertebrae, with the lower thoracic/lumbar spines being the most frequent sites $^{1}$. A psoas abscess complicating Pott's disease could be primary or secondary. Primary psoas abscesses occur due to the haematogenous/lymphatic spread from a
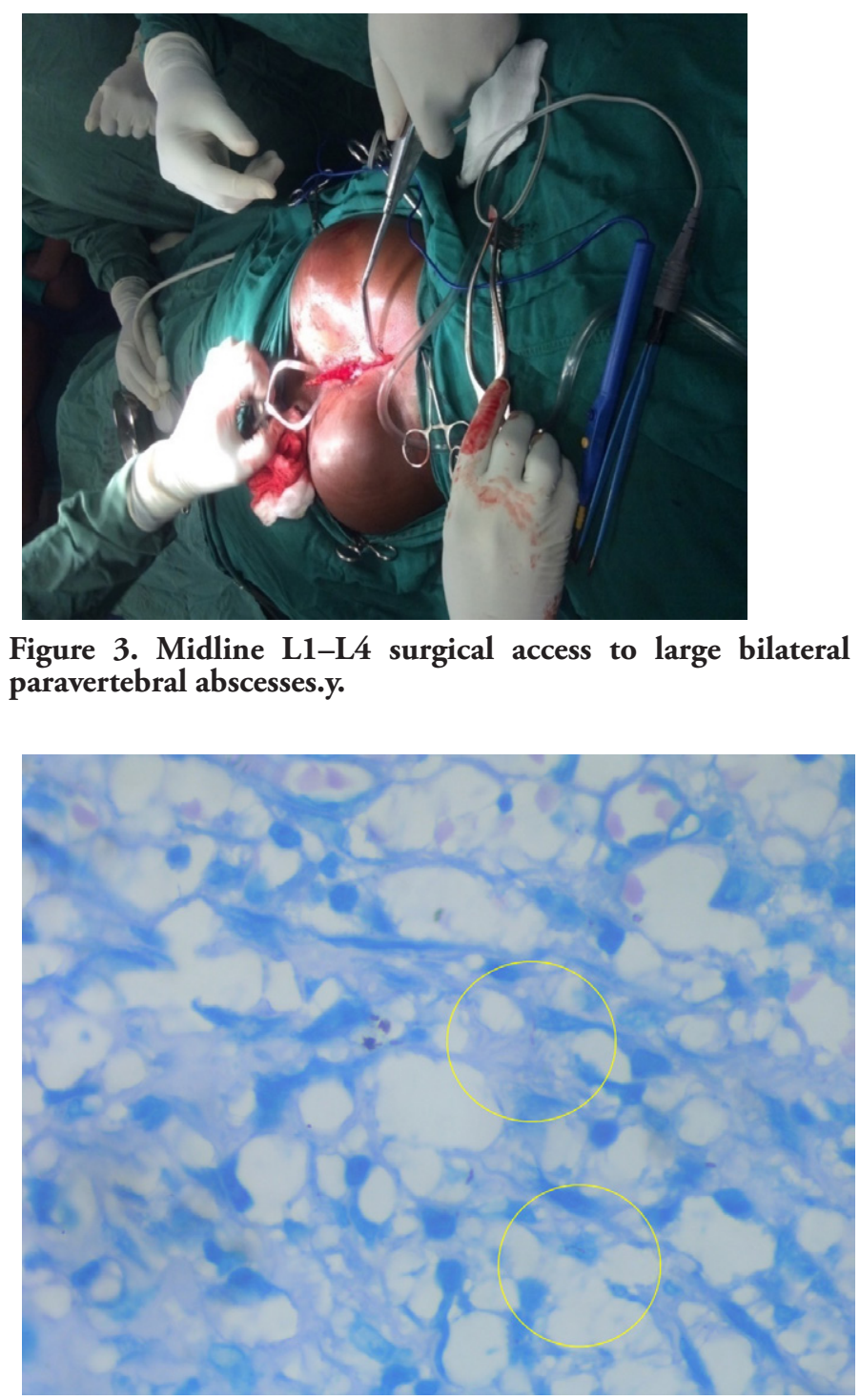

Figure 3. Midline L1-L4 surgical access to large bilateral paravertebral abscesses.y.

distant site, while secondary psoas abscesses develope from the direct extension of a nearby infectious process ${ }^{2} . M$. tuberculosis remains a common cause of psoas abscesses in developing countries ${ }^{3}$. The site of the lesion in our patient is classical for Pott's disease. The peculiarity of her psoas abscess was its bilateral and extensive nature. Bilateral psoas abscess is uncommon ${ }^{2}$.

The opportunity for early diagnosis of spinal TB may be missed because symptoms are non-specific. The average duration of symptoms before diagnosis is 4 months but can be considerably longer ${ }^{4}$. Chronic back pain is usually the earliest and commonest symptom ${ }^{1,4}$. Delayed diagnosis often leads to increased morbidity from complications such as cord compression. Although our patient initially had low back pain, we believe the initial anti-TB therapy that was interrupted altered the progression of the neurological complication. The apparent absence of symptoms of myelopathy might also be related to the site of her lesion. Cord compression is more frequent when the upper/midthoracic spine is involved, as the spinal canal is narrowest between T3 and T10 ${ }^{4}$. Although she had fever and flank pains, psoas spasms which is the third component of the triad of psoas abscess was not evident despite the extensive abscesses. This is not strange as the classical triad occurs in less than $50 \%$ of patients $^{3}$. 
Radiographic changes associated with Pott's manifest relatively late ${ }^{5}$. Plain X-ray usually has a low diagnostic accuracy for both spinal disease and abscess; ultrasonography is diagnostic of psoas abscesses in $70 \%$ of cases while a CT scan is diagnostic of abscesses in $90 \%$ of cases and provides much better details of the bone lesions ${ }^{3,5}$. Magnetic resonance imaging (MRI) is the modality of choice in spinal infection. It is especially helpful in detecting subclinical cord compression syndrome $e^{5}$. The CT scan findings in our patient showed classical features of Pott's disease and psoas abscesses.

Differentiating spinal TB from pyogenic or fungal spondylitis or spinal tumours could be difficult if based on only clinical/ radiographic findings. The non-remarkable chest X-ray, erythrocyte sedimentation rate (ESR) and Mantoux test in our patient compounded the picture initially. However, the patient's history of exposure and the initial response to anti-TB treatment strengthened our resolve to commence therapy before definitive diagnosis. We had no facilities for mycobacterial culture. In most cases of skeletal TB, acidfast bacilli (AFB) staining is negative while mycobacterial cultures are positive in $50 \%$ of cases making bacteriological confirmation of the disease often difficult ${ }^{6}$.

Surprisingly, our patient had normal levels of ESR and C-reactive protein (CRP). Despite its non-specificity, ESR is widely used in sub-Saharan Africa for the demonstration/ evaluation of chronic inflammatory processes such as TB. Although elevation of ESR in patients with Pott's disease is common $^{7,8}$, findings of normal levels of ESR and CRP have been reported in patients with spinal $\mathrm{TB}^{8}$. In a retrospective review of 284 patients with spinal TB in China, $26.8 \%$ of patients were found to have normal ESR $(<20 \mathrm{~mm} / \mathrm{h})$, while normal levels of CRP was observed in $30.2 \%$ of patients ${ }^{8}$. Considering that a repeat ESR in a different laboratory did not show any elevation in our patient, she most likely belongs to the smaller proportion of patients who may have low or normal levels of markers of inflammation despite active TB. It is also possible that the initial anti-TB treatment received by our patient impacted on these parameters. While the underlying mechanism in our patient may not be clear, our observation suggests that a normal level of ESR or CRP should not preclude the diagnosis of TB.

The mainstay of treatment in Pott's is anti-TB drugs for up to 9 months or more? . A four-drug regimen is recommended with isoniazid and rifampicin administered during the whole course of therapy. The role of surgery is debatable. However, indications for surgery include cord compression, spinal deformity with instability, non-response to medical therapy and a large paraspinal abscess ${ }^{10,11}$. Ultrasound/CTguided percutaneous catheter drainage (PCD) and surgical drainage are the two options for abscesses. PCD is less invasive and currently the treatment of choice. However, surgical drainage is indicated when PCD fails, if there is a contraindication to PCD or extensive abdominal pathology. Our patient had no indications for spinal surgery based on expert opinions $\mathrm{s}^{4,10,11}$. To the best of our knowledge, the $6 \mathrm{~L}$ of abscess fluid drained from our patient is unprecedented.

In conclusion, this report highlights a case of Pott's disease with extensive bilateral psoas abscesses. Late presentation and interrupted anti-TB therapy complicated the patient's condition. She was successfully managed with a combination of medical and surgical treatment. TB-related health education should emphasize the availability of anti-TB drugs free-of-charge in DOTS centres. Funding should be provided for surgical management when indicated to ensure satisfactory outcomes.

\section{Authors' contributions}

NI, USU, EOU, MOI and OCO conceived the study. MOI and USU carried out the medical evaluation and management of the case and supervised data collection for the case report. NI carried out the radiological evaluation of the case. EOU conducted the neurosurgical assessment and management of the case while OCO conducted the pathological investigation of the case. MOI conducted literature search. MOI, NI, USU, EOU and OCO drafted the manuscript and all authors critically reviewed the manuscript for intellectual content. All authors approved the final version of the manuscript.

\section{Conflict of interest}

The authors report no conflict of interest.

\section{Funding}

No funding was received.

\section{Acknowledgements}

We are grateful to all the members of the Radiation Medicine, Infectious Diseases, Neurosurgery and Histopathology teams that managed the patient. Her laboratory investigations, subsistence and ancillary treatments were largely funded by this team of doctors. We are also indebted to the nurses and some other patients in the female surgical ward for contributing to the patient's subsistence. The Executive Governor of Enugu State, the Medical Social Welfare Department and the Hospital Management of UNTH are deeply appreciated for the waiver granted for the patient's admission and surgical fees.

\section{References}

1. Njoku CH, Makusidi MA, Ezunu EO. Experiences in management of Pott's paraplegia and paraparesis in medical wards of Usman Danfodiyo University Teaching Hospital, Sokoto, Nigeria. Ann Afr Med. 2007;6(1):22-5. doi: 10.4103/1596-3519.55735.

2. Shields D, Robinson P, Crowley TP. Iliopsoas abscess - A review and update on the literature. Int J Surg. 2012;10(9):466-9. doi: 10.1016/j. ijsu.2012.08.016.

3. Adelekan MO, Taiwo SS, Onile BA. A review of psoas abscess. Afr J Exp Clin Microbiol. 2004;5(1):55-63. doi.org/10.4314/ajcem. v5il. 7360 .

4. Turgut M. Spinal turculosis (Pott's disease): Its clinical presentation, surgical management, and outcome. A survey study on 694 patients. Neurosurg Rev. 2001;24(1):8-13. doi: 10.1007/PL00011973.

5. Rivas-Garcia A, Sarria-Estrada S, Torrents-Odin C, Casas-Gomila L, Franquet E. Imaging findings of Pott's disease. Eur Spine J. 2013;22(4):567-8. doi: 10.1007/s00586-012-2333-9.

6. Lewinsohn DM, Leonard MK, LoBue PA, Cohn DL, Daley CL, Desmond E, et al. Official American Thoracic Society/Infectious Diseases Society of America/Centers for Disease Control and Prevention Clinical Practice Guidelines: diagnosis of tuberculosis in adults and children. Clin Infect Dis. 2017;64(2):111-5. doi: 10.1093/ cid/ciw778.

7. Mulleman D, Mammou S, Griffoul I, Avimadje A, Goupille P, Valat JP. Characteristics of patients with spinal tuberculosis in a French teaching hospital. Joint Bone Spine. 2006;73(4):424-7. doi:10.1016/j. jbspin.2005.10.013.

8. Wang H, Li C, Wang J, Zhang Z, Zhou Y. Characteristics of patients with spinal tuberculosis: seven-year experience of a teaching hospital in Southwest China. Int Orthop. 2012;36(7):1429-34. doi:10.1007/ 
s00264-012-1511-z.

9. Rasouli MR, Mirkoohi M, Vaccaro AR, Yarandi KK, RahimiMovaghar V. Spinal tuberculosis: Diagnosis and management. Asian Spine J. 2012;6(4):294-308. doi: 10.4184/asj.2012.6.4.294.

10. Djientcheu VP, Mouafo Tambo FF, Ndougsa IS, Ndougsa IS, Eloundou NJ, Kounan Tsala N, et al. The role of surgery in the management of Pott's disease in Yaoundé. A review of 43 cases.
Orthop Traumatol Surg Res. 2013;99(4):419-23. doi:10.1016/j. otsr.2012.12.022.

11. Elnaim AL. Bilateral psoas abscess and extensive soft tissue involvement due to late presentation of Pott's disease of the spine. Indian J Surg. 2011;73(2):161-2. doi: 10.1007/s12262-010-0206-1. 
